\title{
Effects of 1-Methylcyclopropene and Wrapping Material on Postharvest Qualities of Spine Gourd (Momordica dioica)
}

\author{
Wijesinghe, G.P.M., Kumara, G.D.K. \& Kumara, J.B.D.A.P. \\ madushaniwijesinghe6@gmail.com,gdonkk@yahoo.com,arunajbd@gmail.com \\ Faculty of Agricultural Sciences, Sabaragamuwa University of Sri Lanka, Sri Lanka
}

\begin{abstract}
Spine gourd (Momordica dioica) is a tropical under-utilized vegetable (known as King of Gourds) that belongs to family Cucurbitaceae. It has higher demand in Asia and Sri Lanka due to its distinct taste and promising health properties known for over thousands of years. However, vulnerability to postharvest damages due to climacteric ripening behavior results in short shelf-life of this commodity. It significantly affects their market potential. The present study attempts to extend shelf-life while maintaining postharvest qualities in spine gourd by using 1-methylcyclopropene (1-MCP) and LowDensity Polyethylene (LDPE) wrapping at ambient temperature $\left(27 \pm 1{ }^{\circ} \mathrm{C}\right)$. The experiment was conducted according to Completely Randomized Factorial Design using eight treatment combinations: $0,0.5,1.0,1.5 \mu \mathrm{L} \mathrm{L}^{-1} 1-\mathrm{MCP}$ treated for 15 hours and stored with and without LDPE wrapping under ambient temperature. Physical parameters; fresh weight loss, firmness, peel color changes and chemical parameters; total soluble solids, titratable acidity were evaluated five days after treatment. Fresh weight loss significantly declined in wrapped spine gourd fruits. The highest firmness was observed in chemically treated fruits with LDPE wrapping. Yellowing of fruits decreased with $0.5 \mu \mathrm{L} \mathrm{L}^{-1} 1-\mathrm{MCP}$ and LDPE wrapping. Total soluble solid content was lesser in fruit wrapped with LDPE. Thus, it can be concluded that some postharvest qualities of spine gourd are positively affected by $0.5 \mu \mathrm{L} \mathrm{L}^{-1} 1-\mathrm{MCP}$ concentration with LDPE wrapping.
\end{abstract}

Keywords: 1-methylcyclopropene, Low-Density Polyethylene, Postharvest Quality, Shelf-life, Spine gourd

\section{Introduction}

Postharvest management is the main quality dependent factor of any harvested horticultural commodity. Freshly harvested commodities are made to undergo postharvest treatments to minimize losses and increase its shelf-life. Worldwide postharvest losses are as high as 30 to $40 \%$ in developing countries due to ineffective postharvest treatments (Jiang et al., 1999). Spine gourd (Momordica dioica) is a perennial, dioecious, cucurbitaceous vegetable with high demand in Asian countries (Ratnayake et al., 2019). It is referred to as "King of Gourds" due to its high nutritional value (Saha et al., 1991). Fruit of spine gourd is free from cholesterol and highly energetic (45.74Kcal) (Ram et al., 2004). It contains a remarkable amount of carbohydrates, protein, fat, fiber, vitamins and minerals that increase its market demand, for both processed and fresh consumption. Jain and Singhai (2010), 
reported that the fruits are useful in the treatment of heart diseases, urinary discharges, excessive salivation, asthma, fever, leprosy and tumors. Also, fruit powder is used to induce sneezing, and leading to nasal clearing. Spine gourd shows some climacteric behavior which is more or less similar to bitter gourd (Payal, 2013). As a consequence, preservation of this important vegetable degrades rapidly resulting yellowing, softening and senescence.

Ethylene $\left(\mathrm{C}_{2} \mathrm{H}_{4}\right)$ is a ripening hormone of climacteric fruits. At a certain maturation stage, ethylene is linked to its bindingsites in the cell and promotes ripening and senescence of fruits (Lelievre et al., 1997). 1-Methylcyclopropene (1-MCP) is an excellent and eco-friendly ethylene inhibitor that can retard the ripening of fruits and vegetables by binding the ethylene receptors and inhibiting formation of ethylene receptor complexes (Hu et al., 2017). Then 1-MCP can reduce the actions of the ethylene in fruit reducing the rate of fruit softening, peel color changes, sugar productions and also fresh weight losses (Jiang and Joyce, 2002; Wijesinghe et al., 2021). The chemical is regarded as a safe and widely-used product in post-harvest management of horticultural crops (Mahajan et al., 2014; Tomala et al., 2020; Wijesinghe et al., 2021).

Low density polyethylene (LDPE) wrapping is a common postharvest technique used to increase shelf life of different commodities. It creates a modified atmosphere around the fruits. Normally, edible spine gourd fruits are rich with $84.1 \%$ moisture and also spines like projections results large surface area/volume ratio (Singh et al., 2009). The high specific surface area of the fruit leads to increased moisture loss through fruit surface resulting fresh weight loss, wilting and ultimately short shelf life with low quality. Wrapping greatly reduce moisture loss and also reduces the respiration rate, chilling injuries, deformation, blemishes and the fruit decay (Mohommad and Wickham, 1993). Therefore, the present study was carried out to evaluate the shelf-life and postharvest qualities of the spine gourd treated with 1-MCP and low-density polyethylene wrapping. Accordingly, objectives of the present study are to improve the shelf-life and postharvest qualities of spine gourd by 1-MCP and by LDPE wrapping.

\section{Materials and Methods}

The experiment was conducted at the Sabaragamuwa University of Sri Lanka as Completely Randomized Design (CRD) with factorial structure. Uniform spine gourd fruits, harvested freshly at horticulture maturity were treated with Agrofresh ${ }^{\mathrm{TM}}$, in powder form, having $4 \%$ active ingredient of 1-MCP. The experiment design was two factor $(2 \times 4)$ factorial on basis of CRD. Accordingly, four levels of 1-MCP: $0 \mu \mathrm{L} \mathrm{L}^{-1}, 0.5 \mu \mathrm{L} \mathrm{L}^{-1}, 1.0$ $\mu \mathrm{L} \mathrm{L}^{-1}$ and $1.5 \mu \mathrm{L} \mathrm{L}^{-1}$ (1-MCP gas volume/ chamber volume) and two levels of wrapping: with LDPE and without LDPE wrapping. The eight treatments are shown in the Table 1. Each treatment has three replicates. 
Table 1.

\section{Eight treatments used for the experiment}

Notation Combination

T1 $\quad 0.0 \mu \mathrm{L} \mathrm{L}^{-1} 1-\mathrm{MCP}$ and without wrapping (Control)

$\mathrm{T} 2$

$0.5 \mu \mathrm{L} \mathrm{L}^{-1} 1-\mathrm{MCP}+$ without wrapping

T3

$1.0 \mu \mathrm{L} \mathrm{L}^{-1} 1-\mathrm{MCP}+$ without wrapping

T4

$1.5 \mu \mathrm{L} \mathrm{L}^{-1} 1-\mathrm{MCP}+$ without wrapping

T5

$0.0 \mu \mathrm{L} \mathrm{L}^{-1} 1-\mathrm{MCP}+$ with wrapping

T6

$0.5 \mu \mathrm{L} \mathrm{L}^{-1} 1-\mathrm{MCP}+$ with wrapping

T7

$1.0 \mu \mathrm{L} \mathrm{L}^{-1} 1-\mathrm{MCP}+$ with wrapping

T8
Where, W1 = Initial weight of fruits $(\mathrm{kg})$, $\mathrm{W} 2=$ Weight of fruits after five days $(\mathrm{kg})$

Firmness was determined by using fruit firmness tester (FHP-803, Agriculture Solutions LLC, USA). The color of the fruit peel was determined as $L^{*}, a^{*}$ and $b^{*}$ values using a Colorimeter (CR-400, Minolta, Osaka, Japan). The Total Soluble Solids content of fruits was estimated using the Digital refractometer (ORD 85BM, Kern Optics). The Titratable Acidity (TA) was determined by the method described by Kumari et al. (2017). Data were subjected to statistical analysis using analysis of variance (ANOVA) and Duncan's Multiple Range Test (DMRT) for pairwise comparison of means at the $5 \%$ significance level.

\section{Results and Discussion Fresh weight loss (FWL)}

Weight losses during storage period were expressed in terms of grams per $\mathrm{kg}$ of fresh weight. As shown in Table 2, the analysis of variance found that the eight treatments are significantly different $(p<0.05)$. Furthermore, it was found that there was no significant interaction effect between 1-MCP and wrapping on FWLs during the storage period (Table 2). Treatment means are shown in Table 3.

Application of wrapping significantly decreased the weight loss in spine gourd fruits $(p<0.001)$. Accordingly, lower fresh weight loss was revealed by wrapped fruits (T5, T6, T7 and T8) than the non-wrapped fruits (T1, T2, T3, T4). DMRT confirmed that the mean fresh weight loss values of all 1-MCP treated fruits were not significantly different 
from control treatments (T1 and T5). LDPE fresh weight loss. This is in agreement with may act as a gas barrier that greatly reduces Singh et al. (1979) that reported lower fresh gas exchange in the fruits and also modify weight loss in bitter gourd fruits packed with the atmosphere around the fruit by reducing 400-gauge polyethylene at room temperature.

Table 2.

Summary of the ANOVA table for each variable

Source

Variables

\begin{tabular}{lccccccccc} 
& df & FWL & FF & FC_B & FC_G & FC_Y & TSS & TA \\
\hline Between treatments & 7 & $*$ & $*$ & $*$ & $\mathrm{~ns}$ & $*$ & $*$ & $\mathrm{~ns}$ \\
\hline Between levels of 1-MCP & 3 & $\mathrm{~ns}$ & $*$ & $*$ & $\mathrm{~ns}$ & $*$ & $\mathrm{~ns}$ & $\mathrm{~ns}$ \\
\hline Wrapping vs without wrapping & 1 & $*$ & $*$ & $*$ & $\mathrm{~ns}$ & $*$ & $*$ & $\mathrm{~ns}$ \\
\hline 1-MCP*Wrapping & 3 & $\mathrm{~ns}$ & $*$ & $*$ & $\mathrm{~ns}$ & $\mathrm{~ns}$ & $*$ & $\mathrm{~ns}$ \\
\hline
\end{tabular}

* Significant at least 5\%, ns: not significant at least 5\%, df: Degree of freedom, FWL: Fresh weight loss, FF: Fruit firmness, FC_B: Fruit colour brightness, FC_G: Fruit color greenness, FC_Y: Fruit colour yellowness, TSS: Total Soluble Solids, TA: Titratable Acidity

\section{Fruit firmness (FF)}

Firmness of spine gourd fruits at five days after treatments was given in Table 3. ANOVA in Table 2 confirmed that fruit firmness among 8 treatments is significant. Furthermore, it was found that interaction between 1-MCP and LDPE wrapping was significant at 0.05 level (Table 2). Based on DMRT at 5\% level, highest fruit firmness was observed in 1.0 and $1.5 \mu \mathrm{L} \mathrm{L}^{-1} 1-\mathrm{MCP}$ with wrapping (T7 and $\mathrm{T} 8$ ) and that was lowest in $\mathrm{T} 1$ and $\mathrm{T} 5$ treatments ( $0.0 \mu \mathrm{L} \mathrm{L}^{-1} 1$-MCP with or without wrapping). This result revealed that, LDPE wrapping alone may not be effective on preservation of fruit firmness. However, more promising results could be achieved when 1-MCP is applied with wrapping (T6, T7 and T8). Fruit softening or loss of firmness is mainly associated with cell wall breakdown and loss of moisture (Paniagua et al., 2013). According to present study, wrapping has strong negative effect on fruit moisture loss. Moreover, present study revealed that wrapping alone may not retard loss of firmness. Therefore, application of 1-MCP is more effective when fruits were wrapped with LDPE wrapping and in agreement with Mohommad and Wickham (1993), it reported lesser fruit firmness drop in wrapped fruits than the non-wrapped. 
Table 3.

Treatment means, fresh weight loss and firmness of spine gourd fruits at five days after treatments

\begin{tabular}{lll}
\hline \multirow{2}{*}{ Treatment } & Fresh weight loss & Firmness \\
\cline { 2 - 3 } & Mean $(\mathbf{g} / \mathbf{k g})$ & Mean $(\mathbf{N})$ \\
\hline T1 & 389.41 & 42.27 \\
\hline T2 & 347.46 & 126.00 \\
\hline T3 & 325.68 & 68.33 \\
\hline T4 & 354.02 & 58.70 \\
\hline T5 & 124.88 & 28.93 \\
\hline T6 & 102.21 & 183.00 \\
\hline T7 & 95.81 & 207.00 \\
\hline T8 & 104.17 & 204.66 \\
\hline
\end{tabular}

\section{Fruit color brightness (FC_B)}

Mean values of brightness of fruits (measured as $\mathrm{L}^{*}$ value) were given in Table 4. Accordingto the results in Table 2, 1-MCP and LDPE wrapping interaction was significant at 0.05 level. Among the treatments, highest brightness value 52.87 was observed in T4 (1.5 $\mu \mathrm{L} \mathrm{L}^{-1}$ without wrapping) treatment. However, that was not significantly different from $\mathrm{T} 1 \quad\left(0.0 \mu \mathrm{L} \quad \mathrm{L}^{-1} \quad 1-\mathrm{MCP}\right.$ without wrapping) and $\mathrm{T} 5\left(0.0 \mu \mathrm{L} \mathrm{L}^{-1}\right.$ with wrapping $)$ treatments. Lowest brightness was observed in $\mathrm{T} 8\left(1.5 \mu \mathrm{L} \mathrm{L}^{-1}\right.$ with wrapping) and that was not significantly different from $\mathrm{T} 1$ and $\mathrm{T} 5$ treatments. The immature fruits may have the highest brightness and the value decrease with the fruit maturation (Khandaker et al., 2018). However, present study revealed that application of $1-\mathrm{MCP}$ with or without wrapping may not have any negative effect on fruit brightness.

\section{Fruit color greenness (FC_G)}

Greenness (measured as a* value) of the fruits was given in Table 4. According to Table 2, 1-MCP or LDPE wrapping did not significantly have an effect on greenness of the fruit. It could be due to greater variability in greenness of Spine gourd fruit at maturity and it is in agreement with Bawara et al. (2010) who reported fruit colour variability at maturity

\section{Fruit colour yellowness (FC_Y)}

Mean values of yellowness (measured as $b^{*}$ value) of the fruits are given in Table 4 . According to the results in Table 2 it can be concluded that the two factors (1-MCP and LDPE wrapping) significantly decreased the development of fruit yellow color. Yellow color development was lowest in wrapping (T5, T6, T7 and T8) compared to without 
wrapping treatments (T1, T2, T3 and T4) Moreover lowest yellow colour development was observed at 1 -MCP 0.5 and $1.0 \mu \mathrm{L}$ $\mathrm{L}^{-1}$ and those treatments were significantly different from the rest. Present findings are in agreement with Li et al. (2020) that reported good effect of 1-MCP on mango peel colour.

Table 4.

Mean color values of spine gourd at five days after treatments

\begin{tabular}{lccc}
\hline \multirow{2}{*}{ Treatment } & Fruit brightness & Greenness & Yellowness \\
\cline { 2 - 4 } & Mean of $\mathbf{L}^{*}$ & Means of $\mathbf{~}^{*}$ & Mean of $\mathbf{b}^{*}$ \\
\hline T1 & 49.64 & -11.35 & 39.62 \\
\hline T2 & 45.58 & -13.42 & 31.65 \\
\hline T3 & 42.87 & -6.57 & 41.95 \\
\hline T4 & 52.87 & -7.71 & 44.29 \\
\hline T5 & 48.49 & -12.21 & 38.06 \\
\hline T6 & 43.26 & $-12,27$ & 32.17 \\
\hline T7 & 44.32 & -13.47 & 32.04 \\
\hline T8 & 41.61 & -7.72 & 34.43 \\
\hline
\end{tabular}

Total Soluble Solids (TSS)

The mean values of total soluble solid contents were given in Table 5. For TSS too, the interaction between 1-MCP and LDPE wrapping was significant at 0.05 level. However, wrapping significantly affected on TSS and greater TSS was observed in T1 (without 1-MCP and LDPE wrapping) compared to T5 (without 1-MCP with wrapping). This is in agreement with Pongener et al. (2011) that reported slow TSS development in polyethylene wrapped peach fruits. The delayed increase in TSS content in spine gourd fruits might be due to retarded ripening and senescence processes which reduced the conversion of starch into sugars. In contrast to wrapping, 1-MCP did not result in any significant effect on TSS.

\section{Titratable Acidity (TA)}

Mean values of titratable acidity were given in Table 5. In this case results of the treatments were not significantly different (Table 2). Moreover, no significant difference was found between 1-MCP, between wrapping and no wrapping and interaction. There was no significant effect of 1-MCP or wrapping on titratable acidity of spine gourd. It may be due to 1-MCP and wrapping being ineffective to change the citric acid level in the fruit. 
Table 5.

Titratable acidity of spine gourd at five days after treatments

\begin{tabular}{lcc}
\hline \multirow{2}{*}{ Treatment } & Total soluble solid & Titratable acidity \\
\cline { 2 - 3 } & Mean (\%) & Mean (\%) \\
\hline T1 & 8.97 & 1.50 \\
\hline T2 & 5.53 & 0.92 \\
\hline T3 & 6.68 & 1.15 \\
\hline T4 & 6.70 & 1.14 \\
\hline T5 & 4.40 & 0.91 \\
\hline T6 & 6.52 & 0.90 \\
\hline T7 & 5.50 & 1.21 \\
\hline T8 & 5.83 & 1.50
\end{tabular}

\section{Conclusions}

The fresh weight loss significantly declined in wrapped spine gourd fruits and the higher firmness was observed in chemically treated fruits with LDPE wrapping than without wrapping. Yellowing of fruits decreased with 1-MCP and LDPE wrapping. Total soluble solid content was lesser in fruits wrapped with LDPE. Thus, it can be concluded that some postharvest qualities of spine gourd are positively affected by $1-\mathrm{MCP}$ (even at $0.5 \mu \mathrm{L}$ $\mathrm{L}^{-1}$ ) treatment and LDPE wrapping. Further studies are suggested to evaluate the shelf life and postharvest qualities of Spine gourd using different wrapping materials and 1-MCP concentrations.

\section{References}

Bawara, B. Dixit, M. Chauhan, N.S. Dixit, V.K. \& Saraf, D.K. (2010). Phytopharmacology of Momordica dioica Roxb.ex.Willd:AReview. International Journal of Phytomedicine, 2, 1-9.

Dong, L. Lurie,S. \& Zhou,H. (2002). Effect of 1-methylcyclopropene on ripening of Canino apricots and Royal Zee plums. Postharvest biology and technology,24,135-145.

Hu, Z., Tang, C., He, Z., Lin, J. \& Ni, Y. (2017). 1-Methylcyclopropene (MCP)-containing cellulose paper packaging for fresh fruit and vegetable preservation: A review. BioResources, 12(1), 2234-2248. 
Jain, A. \& Singhai, A.K. (2010). Effect of Momordica dioica Roxb. On gentamicin model of acute renal failure. Natural Products Research 24:1379-1389.doi: $10.1080 / 14786410802267569$.

Jiang, Y. M. \& Joyce, D. C. (2002). 1-methylcyclopropene treatment effects on intact and fresh-cut apple. Journal of Horticultural Sciences and Biotechnology,77,143-151.

Jiang, Y. M. Joyce, D. C. \& Macnish, A. J. (1999). Extension of the shelf-life of banana fruit by 1-methylcyclopropene in combination with polyethylene bags. Postharvest Biology and Technology, 16, 187-193.

Khandaker, M.M. Amirah, F.N. Majrashi, A. Sajili, M.H. Mohdm K.S.1, \& Mat, N. (2018). Peel colour, anthocyanin, TSS content and sensory evaluation of some common fruits: A comparative study. Australian Journal of Crop Science, 12(11),1788-1795.

Kumari, S.C. Kumar, A.P. Harish. Shekawat, S. Narpat, S. \& Shekhawat. (2017). An improved micropropagation system,ex vitro rooting and validation of genetic homogeneity in wild female Momordica dioica: an underutilized nutraceutical vegetable crop. Physiology and Molecular biology of plants, 23, 713722.

Leliévre, J.M. Latché, A. Jones, B. Bouzayen, M. \& Pech, J.C. (1997). Ethylene and fruit ripening. Physiologia Plantarum,1001,727-739.
Li, L. Li, C. Sun, J. Sheng, J. Zhou, Z. Xin, M.Yi, P. He, X. Zheng, F. Tang, Y. Li, J \& Tang, J. (2020). The effects of 1-Methylcyclopropene in the regulation of antioxidative system and softening of mango fruit during storage. Journal of Food Quality, https://doi. org/10.1155/2020/6090354.

Mohommad, M. \& Wickham, D.L. (1993). Extension of Bitter gourd (Momordica charantia L.) storage life through the use of reduced temperature and polythene wraps. Journal of food quality, 16, 371382.

Paniagua, A.C. East, A.R. Hindmarsh,J.P. \& Heyes, J.A. (2013). Moisture loss is the major cause of firmness change during postharvest storage of blueberry. Postharvest Biology and Technology, 79, 13-19.

Payal, T. Shah. \& Ramana, T.V. (2013). Physiological, Biochemical and Cellular changes associated with the ripening of Bitter-less Bitter gourd (Momordica dioica Roxb.Ex Willd.) fruits. Journal of Engineering and Science, 2(7),1-5.

Pongener, A. Mahajan, B.V.C. \& and Singh, H. (2011). Effect of different packaging films on storage life and quality of Peach fruits under cold storage conditions. Indian Journal of Horticuture, 68(2), 240-245.

Ram, D. Kumar, S. Verma, A. \& Rai, M. (2004). Variability analysis of underutilized nutritive vegetable 
Kartoli: Indian collection. Cucurbit Genetics Cooperative Report 27: 6668.

Ratnayake, S.S., Kumar, L. \& Kariyawasam, C.S. (2019). Neglected and underutilized fruit species in Sri Lanka: Prioritisation and understanding the potential distribution under climate change. Agronomy. DOI:10.3390/ agronomy 10010034.

Saha, M.C. Begum, R.A. Hamid, M.M. \& Hossain, S.M.M. (1991). Genetic variability and character association in teasel gourd. Bangladesh Horticulture, 19: 25-30.

Singh, D. Bahadur, V. Singh, D.B. \& Ghosh, G. (2009). Spine gourd (Momordica dioica): an under-utilized vegetable with high nutritional and medicinal values. ISHS ,ActaHorticulturae, 809,241-248.

Singh, B.P. \& Dhankhar, B.S. (1979). Effect of growth regulators and prepackaging on the storage like of Okra. Haryana Agricultural University, Journal of Research, 10(3), 398-402.

Wijesinghe, G.P.M. Kumara, G.D.K. \& Kumara, J.B.D.A.P. (2021). Effect of 1-Methylcyclopropene on shelf-Life and postharvest qualities of four Annona (Annona spp.) species in Sri Lanka. Journal of Food and Agriculture, 14(I), $1-17$. 